\title{
Corrosion Protection of Steel by Volatile Corrosion Inhibitors: Vapor Analysis by Gas-Diffusion Microextraction and Mass Loss and Electrochemical Impedance in $\mathrm{NaCl}$ Deliquescence Tests
}

\author{
Marco A. G. Valente Jr., ${ }^{\oplus a}$ Luís M. Gonçalves, ${ }^{\oplus b, c}$ Juliano Passaretti Filho, ${ }^{d}$ \\ Arnaldo A. Cardoso, ${ }^{d}$ José A. Rodrigues, ${ }^{c}$ Cecilio S. Fugivara ${ }^{a}$ and Assis V. Benedetti ${ }^{\oplus * a}$ \\ ${ }^{a}$ Departamento de Físico-Química, Instituto de Química, Universidade Estadual Paulista (Unesp), \\ 14800-060 Araraquara-SP, Brazil \\ ${ }^{b}$ Departamento de Química Fundamental, Instituto de Química, Universidade de São Paulo (USP), \\ 05508-000 São Paulo-SP, Brazil \\ 'REQUIMTE/LAQV, Departamento de Química e Bioquímica, \\ Faculdade de Ciências da Universidade do Porto, 4169-007 Porto, Portugal \\ ${ }^{d}$ Departamento de Química Analítica, Instituto de Química, Universidade Estadual Paulista (Unesp), \\ 14800-060 Araraquara-SP, Brazil
}

\begin{abstract}
A new methodology using gas-diffusion microextraction (GDME) was developed for the analysis of volatile corrosion inhibitors (VCIs). The evaluation of the inhibition efficiency and corrosion rate $(\mathrm{v})$ was performed by $\mathrm{NaCl}$ deliquescence tests and correlated with measurements of polarization resistance $\left(\mathrm{R}_{\mathrm{p}}\right)$ obtained from electrochemical impedance spectroscopy (EIS) analysis and with the $\mathrm{pH}$ resulting from the atmosphere of the inhibitor $\left(\mathrm{pH}_{\mathrm{GDME}}\right)$. The correlation obtained between $v$ and $\mathrm{pH}_{\mathrm{GDME}}$ indicates that the higher the value of $\mathrm{pH}_{\mathrm{GDME}}$ the lower the corrosion rate. The Raman spectra of steel was used to monitor in situ adsorption of VCI and the surface modifications caused by the inhibitors. The scanning electron microscopy (SEM) images corroborate the data of $v$, both indicating that the cyclohexylamine vapor showed the best corrosion resistance performance.
\end{abstract}

Keywords: corrosion, derivatization, steel, volatile corrosion inhibitors, vapor phase inhibitors

\section{Introduction}

In the globalized world, metal parts are produced far from the end user. Thus, transportation and storage steps are essential for linking production and consumption. Metal parts produced in steel are especially susceptible to corrosion processes during storage and transport. The atmosphere of the environment is critical, in particular when humidity and the presence of pollutants favor such processes. ${ }^{1}$ This can be prevented not only by controlling the surrounding atmosphere but also by employing corrosion inhibitors. ${ }^{1}$ Among the several types of inhibitors, there are the vapor phase inhibitors, also known as volatile corrosion inhibitors (VCIs), which interact with the exposed surface of the metal. The main advantage of these VCIs is gasphase transport, which enables them to reach the exposed

*e-mail: assis.v.benedetti@unesp.br metallic surfaces anywhere. An important characteristic of compounds that act as VCIs is the vapor pressure at room temperature (ca. $25^{\circ} \mathrm{C}$ ). Since some organic compounds have high vapor pressure at room temperature, they can also act as corrosion inhibitors, and therefore they could be used as VCIs.

VCIs usually contain mixtures of amine derivatives based on carboxylic acids such as amine caprylates and are free of products not recommended by the automotive industry and environmental legislation such as nitrites. The amino group-derivative compounds are used as VCIs because they are generally volatile and their chemical structures have high electronic density, with the presence of oxygen, sulfur, nitrogen and/or unsaturated bonds. ${ }^{1-6}$ The action of the VCIs on the metal surface can be described in two ways: (i) molecules are volatilized and broken when they reach the metal surface; or (ii) the inhibitor dissociates prior to reaching the metal surface and saturates 
the air in contact with the metal with the protecting groups. Equilibria of the volatilization system and the adsorption on the surface may be influenced by the amount of water vapor present in the environment, especially if the solubility of the VCI is high in such medium. The $\mathrm{pH}$ value of the adsorbed thin electrolytic layer $\left(\mathrm{pH}_{\mathrm{ATEL}}\right)$ depends on the solubility of the VCI on the adsorption layer. It is known that weak volatile bases and acids are better adsorbed in the $\mathrm{pH}$ range from 5.5 to $8.5^{7}$ and this may influence the corrosion protection efficiency as well as the chemical composition on the metal surface.

After the formation of a VCI vapor saturated atmosphere, the compound must condensate over the aimed surface creating a layer of protection against corrosion. ${ }^{1-3}$ The VCI film deposited on the metal surface is very thin and easy to remove, making possible subsequent surface treatments such as phosphate coating or electrophoretic painting. ${ }^{2}$ VCIs are particularly useful in the long distance container transport. The use of sealed packaging favors the formation of VCI saturated atmosphere. The disadvantage is the time required to saturate the closed atmosphere with VCIs. ${ }^{2} \mathrm{VCIs}$ with high vapor pressure quickly saturate the atmosphere; however, they tend to be less efficient in longer times due to depletion of the emission source of the VCI. The way to use and apply the VCI is varied. They can be applied as powder, as pellets, impregnated on the surface of the material used in the packaging, or in the form of solutions applied as a spray. ${ }^{7}$ Although VCIs have been in use for a long time, the mechanism by which these compounds act protecting the metal is still not completely clear. Recognizing when atmospheric saturation is achieved with the VCI vapor is the main difficulty in proposing models of action and standards of qualities between different VCIs. The values and equations that establish the vapor pressure of an organic compound as a function of temperature are difficult to use in experiments with VCIs. Indirect methods have been suggested to establish the vapor pressure of compounds that act as VCIs, but they are applied under different conditions from those used with packed corrosion protectors. ${ }^{2}$

Efforts have been made not only to develop new and more efficient VCIs but also to investigate different ways of evaluating their ability to protect materials against environment corrosion. Electrochemical impedance spectroscopy (EIS) ${ }^{8-14}$ has been employed to study the VCIs' ability to protect materials using dissolved VCI in a volume of solution, and a conventional electrochemical cell, but the metal parts are not immersed in solution during storage and transportation. To overcome this issue, EIS studies were conducted in a very thin layer of electrolyte formed from condensation of VCI vapor and/or deliquescence of $\mathrm{NaCl}$ salt to simulate the conditions of atmospheric corrosion, and VCI protection. ${ }^{2,6,15-18}$ Other strategies have been used to evaluate the VCIs' performance, among them one can find theoretical studies, ${ }^{19,20}$ a few studies ${ }^{12,21-23}$ that try to determinate VCIs in the vapor phase and there are works ${ }^{5,17}$ that use a humidity chamber originally developed by Skinner. ${ }^{24}$ The humidity chamber tests show the inhibition efficiency by calculating the mass loss from the sample. ${ }^{24,25}$ In these tests, the sample is conditioned in an environment of high relative humidity and in the presence of the VCIs. However, these studies require long times, and often present results with large variances. More recent studies ${ }^{6,15,16,26}$ add sodium chloride salt to the metal surface and, when the desired values of temperature and humidity are reached, water vapor is absorbed by the salt, a concentrated salt aqueous solution is formed in equilibrium with salt (what is known in this area as deliquescence), a thin adsorbed electrolytic layer (ATEL) is formed, accelerating corrosion.

Although electrochemical methods are relatively fast in comparison to the humidity chamber tests, they have an important drawback. The metal sample must be in contact with a very thick conducting electrolyte layer, a condition that is not observed during storage and transportation of these metal parts, since the metal parts are not immersed in a solution but they are in contact with water vapor, VCI and contaminants as chloride. On the contrary, storage and transport are done in an environment in which moisture can condense and form a thin liquid film or droplets on part of the surface. ${ }^{6}$ Assuming these conditions, electrochemical tests are widely used to obtain the efficiency and VCI adsorption prospects.

Moreover, few studies ${ }^{21,22}$ aim to establish the VCIs mixtures composition in the vapor phase. These studies used thermogravimetric analysis and Fourier transform infrared spectroscopy (TGA-FTIR). Mixtures of amines and carboxylic acids were studied in different proportions (1:1 and 1:3, in terms of molarity), and the results showed that equimolar mixtures were much more effective than 1:3. Since, in the beginning, the vapor mixture is amine enriched, this means the VCI efficiency should change with time. ${ }^{22}$

The gas composition in the vapor phase is related to the emission rate of vapor from the device used, such as sachets and plastic bag impregnated with VCI. The device and composition of organic compounds used play a crucial role in the volatilization and atmosphere saturation. ${ }^{3,27}$ The classical mass loss, in the presence of VCI, ${ }^{7,24,25}$ have not discussed, neither the influence of different devices nor their influence in the corrosion protection process. However, the type of device and the vapor composition play a crucial role in the volatilization and atmosphere saturation step and consist in one of the main contributions of this work for understanding the inhibition efficiency of VCIs. 
This work proposes a method to determine the concentration of VCI vapor in situ, under very similar conditions to those of using VCIs in packages. To determine the concentration of VCI in the vapor phase, the gas diffusion microextraction (GDME) technique ${ }^{28}$ was used. The VCI components collected were treated with phenyl isothiocyanate (PITC) and determined using highperformance liquid chromatography with UV detection (HPLC-UV) ${ }^{29}$ The obtained results made it possible to improve the understanding of the emission rate of different $\mathrm{VCI}$ and the time required to saturate the atmosphere. Results were also compared with other methodologies, such as mass loss and EIS, aiming at increasing the knowledge about the action of VCIs on metal surfaces. The VCIs used are commonly tested in the literature ${ }^{5,30}$ as amines, weak acids and amine salts of weak acids. They were chosen due to the diversity in the physicochemical properties and potentiality of being used as a VCI, such as volatility, presence of an heteroatom, water solubility and high electronic density on specific sites.

\section{Experimental}

\section{Chemicals and samples}

All reagents used in this work, except when mentioned otherwise, were of analytical grade and were used without further purification. Ultrapure water from a Direct-Q 3UV water purification system (resistivity not less than $18.2 \mathrm{M} \Omega \mathrm{cm}$ at $298 \mathrm{~K}$ ) was used throughout this work. HPLC grade acetonitrile (ACN) was purchased from Fisher (Porto Salvo, Portugal), nitric acid $\left(\mathrm{HNO}_{3}\right)$ from Qhemis (Jundiaí, Brazil), hydrochloric acid ( $\mathrm{HCl})$ and silver nitrate from Merck (São Paulo, Brazil). Sodium hydrogenphosphate $\left(\mathrm{Na}_{2} \mathrm{HPO}_{4}\right)$, sodium dihydrogenphosphate $\left(\mathrm{NaH}_{2} \mathrm{PO}_{4}\right)$, crotonic acid (CroAc, (E)-2-butenoic acid, $\mathrm{CH}_{3} \mathrm{CH}=\mathrm{CHCOOH}$ ), caprylic acid (CapAc), octanoic acid $\left(\mathrm{CH}_{3}\left(\mathrm{CH}_{2}\right)_{6} \mathrm{COOH}\right)$, cyclohexylamine ( $\left.\mathrm{ChAm}, \mathrm{C}_{6} \mathrm{H}_{11} \mathrm{NH}_{2}\right)$, dicyclohexylamine (DchAm, $\mathrm{C}_{6} \mathrm{H}_{11}-\mathrm{NH}-\mathrm{C}_{6} \mathrm{H}_{11}$ ), sodium chloride $(\mathrm{NaCl})$, hexamethylenetetramine (HmTAm, $\left(\mathrm{CH}_{2}\right)_{6} \mathrm{~N}_{4}$ ), phenylisothiocyanate (PITC) were all purchased from Sigma-Aldrich (St. Louis, USA).

The cyclohexylamine crotonate (ChAm-CroAc), dicyclohexylamine crotonate (DchAm-CroAc), cyclohexylamine caprylate (ChAm-CapAc) and dicyclohexylamine caprylate (DchAm-CapAc) salts were synthesized by mixing the amines ChAm and DchAm in methanol with CroAc and CapAc in an equimolar proportion, followed by dryness at $25{ }^{\circ} \mathrm{C}$. The VCI synthesis was performed according to literature ${ }^{7}$ with minor modifications. Briefly, the carboxylic acid is dissolved in
$1 \mathrm{~mL}$ of methanol, followed by the slowly addition of amine to the flask and afterwards the final solution is placed in a Petri dish for drying at $25^{\circ} \mathrm{C}$.

The ChAm $\left(1.0 \mathrm{~g} \mathrm{~L}^{-1}\right)$, CroAc $\left(1.0 \mathrm{~g} \mathrm{~L}^{-1}\right)$, CapAc $\left(0.5 \mathrm{~g} \mathrm{~L}^{-1}\right)$ and DchAm $\left(0.5 \mathrm{~g} \mathrm{~L}^{-1}\right)$ solutions were prepared in phosphate buffer solution (PBS, pH 7.2, $10 \mathrm{mmol} \mathrm{L}^{-1}$ $\mathrm{Na}_{2} \mathrm{HPO}_{4}$ and $20 \mathrm{mmol} \mathrm{L}^{-1} \mathrm{NaH}_{2} \mathrm{PO}_{4}$ ), subsequent dilutions were also performed in PBS. The PITC solution $(0.5 \% \mathrm{v} / \mathrm{v})$ was prepared in $\mathrm{ACN}$.

The 1005 low carbon steel discs (ArcelorMittal), composed of C: 0.04 wt.\%, Mn: 0.31 wt.\%, S: 0.017 wt.\%, Cr: 0.0004 wt.\% and Fe were embedded in polyether ether ketone (PEEK) with an exposed area of $0.12 \mathrm{~cm}^{2}$ separated about $1 \mathrm{~mm}$ of with each other.

\section{Extraction and derivatization}

The extraction of the VCIs, with the goal of its analysis, was performed by GDME. ${ }^{28,29,31,32}$ A scheme of the GDME is shown in Figure S1 (Supplementary Information (SI) section), $500 \mathrm{mg}$ of the sample were placed inside the chamber and $500 \mu \mathrm{L}$ of PBS were placed inside the GDME probe as the acceptor solution. The GDME worked with a commercial polytetrafluoroethylene (PTFE) membrane (Mitex from Millipore, pore diameter of $5.0 \mu \mathrm{m}$ ) cut into circles of $10 \mathrm{~mm}$ diameter. After the extraction, $250 \mu \mathrm{L}$ of the acceptor solution were transferred to a $2 \mathrm{~mL}$ vial for derivatization. Then, $250 \mu \mathrm{L}$ of PBS, $200 \mu \mathrm{L}$ of $\mathrm{Na}_{3} \mathrm{PO}_{4}\left(0.1 \mathrm{~mol} \mathrm{~L}^{-1}\right)$ and $800 \mu \mathrm{L}$ of PITC $(0.5 \% \mathrm{v} / \mathrm{v}$ in $\mathrm{ACN})$ were added and after $10 \mathrm{~min}$ of reaction at room temperature, $200 \mu \mathrm{L}$ of $\mathrm{HCl}\left(0.1 \mathrm{~mol} \mathrm{~L}^{-1}\right)$ were added to stop the reaction. An aliquot of this solution was then analyzed by HPLC-UV. Derivatization was not performed for CapAc analysis since it could be directly analyzed spectrophotometrically. All these experiments were made in duplicate.

\section{HPLC-UV analysis}

The chromatographic separation was performed according to literature ${ }^{29}$ with minor modifications to improve peak resolution. It was used a PerkinElmer S200 system, with a UV S200 detector and column Gemini $3 \mathrm{u} \mathrm{C}_{18}$ $110 \mathrm{~A}(150 \times 4.60 \mathrm{~mm}$, and $5 \mu \mathrm{m}$ particle size $)$ purchased from Phenomenex. Separations were performed at room temperature, detection wavelength of $240 \mathrm{~nm}$ (except for CapAc, which was $210 \mathrm{~nm}$ ), injection volume of $20 \mu \mathrm{L}$ and constant flow rate of $0.45 \mathrm{~mL} \mathrm{~min}^{-1}$. The mobile phase consisted of ACN (A) and water with $1 \%$ formic acid (B), in the following gradient $(\mathrm{v} / \mathrm{v}): 55 \%$ A during $8 \mathrm{~min}$; changing to $80 \%$ A during $7 \mathrm{~min}$; constant $80 \%$ A during 
$5 \mathrm{~min}$; returning to $55 \%$ A during $5 \mathrm{~min}$; and finally staying at $55 \%$ A for $5 \mathrm{~min}$.

$\mathrm{pH}$ measurements

The $\mathrm{pH}$ was measured with the assistance of GDME. $500 \mathrm{mg}$ of the sample were placed inside the thermostatic chamber at approximately $25{ }^{\circ} \mathrm{C}$. The extracting solution consisted of $2 \mathrm{~mL}$ of water. After $24 \mathrm{~h}$ of extraction, the $\mathrm{pH}$ of the extracting solution was measured. This served as an estimation of the $\mathrm{pH}_{\text {ATEL }}$.

\section{Characterization by surface-enhanced Raman spectroscopy}

The surface-enhanced Raman spectroscopy (SERS) was performed with a micro-Raman Horiba Jobin Yvon LabRAM HR 800, operated with a He-Ne laser at $632.81 \mathrm{~nm}$ and equipped with a CCD camera DU420A-OE-325. The diffraction network was 600 lines $\mathrm{mm}^{-1}$. The signal/noise ratio was optimized making 2 scans per acquisition time of $30 \mathrm{~s}$. SERS analyses were conducted before corrosion and EIS tests for the VCIs with the best and worst performance as inhibitors of steel corrosion, to detect the presence of VCIs on the metallic surface.

Low carbon steel plates $(1 \times 0.7 \times 0.1 \mathrm{~cm})$ were polished with 1200 grit size emery paper, then cleaned in ultrasound isopropanol bath for $5 \mathrm{~min}$. Then the plates were immersed in an $\mathrm{AgNO}_{3}\left(1 \mathrm{mmol} \mathrm{L}^{-1}\right)$ and $\mathrm{HNO}_{3}\left(1 \mathrm{mmol} \mathrm{L}^{-1}\right)$ solution for $10 \mathrm{~min}$ to create a film of silver nanoparticles (AgNPs). The image of the steel surface coated with AgNPs is shown in Figure S2 (SI section). Then the plates were rinsed with water and immersed in a $0.1 \mathrm{~mol} \mathrm{~L}^{-1} \mathrm{HCl}$ solution for $10 \mathrm{~min}$, rinsed again with water and air-dried. The in situ Raman analysis was preceded by $24 \mathrm{~h}$ stabilization period, ${ }^{33}$ and the iron concentration analysis was performed in a $10.0 \mathrm{~mm}$ quartz cuvette (Figure S3a, SI section). A photo of the SERS measurements is displayed in Figure S3b (SI section).

\section{Morphological characterization}

The morphology of the steel surface was analyzed before and after corrosion tests (mass loss test) using a scanning electron microscope JEOL model JSM-7500F coupled to an energy dispersive X-ray spectroscopy (EDS), model Thermo Scientific microanalysis system.

\section{Electrochemical impedance spectroscopy (EIS) measurements}

The EIS measurements were performed with a Bio-Logic VSP potentiostat/galvanostat controlled by
EC-LAB V11.02 software. The electrochemical analyses were performed in a two similar working electrode cell constructed of a glass cylindric body with Teflon end cups (Figure S4, SI section). In one Teflon end cup, a pair of similar low carbon steel discs embedded in PEEK rod about $1 \mathrm{~mm}$ apart in parallel, was fixed. One electrode was connected to the working electrode cable from potentiostat and the other was connected to both reference electrode and auxiliary electrode cables. Each steel disc had an exposed geometric area of $0.12 \mathrm{~cm}^{2}$. The steel discs were polished with 1200 grit size emery paper and then cleaned in an isopropanol ultrasonic bath for $5 \mathrm{~min}$. Subsequently, $40 \mathrm{mg}$ of $\mathrm{NaCl}$ were placed on the two discs surface and then the discs were exposed for $6 \mathrm{~h}$ to an atmosphere containing $1.0 \mathrm{~g}$ of VCI spread around the electrodes (Figure S4, SI section). After the saturation time $(6 \mathrm{~h}), 10 \mathrm{~mL}$ of water were added to increase the relative humidity inside the cell, initiating the deliquescence of the added salt, accelerating the corrosion process. After $4 \mathrm{~h}$ of deliquescence, electrochemical assays were started, i.e., $10 \mathrm{~h}$ after the beginning of the test.

EIS were performed at open circuit by applying a sinusoidal signal of $10 \mathrm{mV}$ rms in a frequency range from $100 \mathrm{kHz}$ to $1 \mathrm{mHz}$, with acquisition of ten data points per frequency decade. All experiments were conducted at $25^{\circ} \mathrm{C}$ and no replicate was made.

\section{Mass loss measurements (corrosion tests)}

The steel plates, embedded in PEEK, with an exposed area of $0.24 \mathrm{~cm}^{2}$, were polished with 1200 grit size emery paper, then cleaned in ultrasound isopropanol bath for $5 \mathrm{~min}$. Afterwards, $20 \mathrm{mg}$ of dried $\mathrm{NaCl}$ were placed on the plates surface and then the plates were exposed to an atmosphere containing VCIs for $24 \mathrm{~h}$. After the saturation time $(24 \mathrm{~h}), 2 \mathrm{~mL}$ of water were added to increase the relative humidity inside the chamber, initiating deliquescence of the added salt, accelerating the corrosion process. After $24 \mathrm{~h}$ of deliquescence, the mass loss was determined. The experiments were made in duplicate and Figure S5 (SI section) shows the experiment setup for the mass loss studies.

To remove the oxides from the surface, steel was immersed during $1 \mathrm{~min}$ in $1 \mathrm{~mL}$ of a $18.5 \% \mathrm{HCl}$ aqueous solution containing $3.5 \mathrm{~g} \mathrm{~L}^{-1} \mathrm{HmTAm}$ to avoid the steel substrate dissolution during the acid attack. ${ }^{34}$ After dissolving the iron oxides, $10 \mu \mathrm{L}$ of $\mathrm{H}_{2} \mathrm{O}_{2}$, in order to oxide the $\mathrm{Fe}^{2+}$ to $\mathrm{Fe}^{3+}$, and $2 \mathrm{~mL}$ of $\mathrm{NH}_{4} \mathrm{SCN}$, the chromophore agent, were added (making a $25 \mathrm{~mL}$ solution). The spectrum had a maximum at the wavelength of $445 \mathrm{~nm}$.

The standard iron solutions were prepared with 
$\left(\mathrm{NH}_{4}\right)_{2} \mathrm{Fe}\left(\mathrm{SO}_{4}\right)_{2} \cdot 6 \mathrm{H}_{2} \mathrm{O}$. Each aliquot was dissolved in $2 \mathrm{~mL}$ of $18.5 \% \mathrm{HCl}$ aqueous solution containing $3.5 \mathrm{~g} \mathrm{~L}^{-1}$ HmTAm, followed by the addition of $10 \mu \mathrm{L}$ of $10 \% \mathrm{H}_{2} \mathrm{O}_{2}$ and $2 \mathrm{~mL}$ of $0.190 \mathrm{~mol} \mathrm{~L}^{-1}$ of $\mathrm{NH}_{4} \mathrm{SCN}{ }^{34}$

The spectrophotometric measurements were performed in a Hitachi U-2000 using $10.0 \mathrm{~mm}$ quartz cuvettes.

\section{Results and Discussion}

\section{Detection of the different VCls}

The obtained parameters for the HPLC-UV analysis are displayed in Table 1. The four samples in Table 1 are the precursor compounds of the VCI salts, that is, amines and carboxylic acids. The sublimation of VCI salts often occurs through a dissociation mechanism ${ }^{35}$ and, therefore, only the four precursors were detected in the vapor phase. In addition, the peaks analyzed for VCI salts in the chromatograph are the precursors that make up this salt. Figures $1 \mathrm{a}$ and $1 \mathrm{~b}$ show the concentration of the compounds in phosphate buffer $\mathrm{pH} 7.2$ (acceptor) stored in vials with 23 and $6 \mathrm{~mm}$ openings. The mean concentration values were obtained from 2 replicates. In the $23 \mathrm{~mm}$ aperture bottle experiments, the ChAm compound is detected rapidly with time periods lower than $10 \mathrm{~min}$. The CroAc and DchAm are detected in times between 10 and $100 \mathrm{~min}$, respectively. CapAc is only detected at times greater than $100 \mathrm{~min}$. The detected sequence from short to long times coincides with the vapor pressure values of each compound at $25{ }^{\circ} \mathrm{C}$ : $\mathrm{ChAm}(10 \mathrm{mmHg})>\mathrm{CroAc}(0.32 \mathrm{mmHg})>$ DchAm $(0.034 \mathrm{mmHg})>$ CapAc $(0.003 \mathrm{mmHg})$. In the $6 \mathrm{~mm}$ aperture vial trials, the detected sequence is the same as in the aperture $23 \mathrm{~mm}$ vial, however, the compounds take longer to be detected, as the aperture is smaller, so the quantity of compound that diffuses also is lower ${ }^{27}$ and, therefore, the CapAc compound was not detected at a time lower than $1000 \mathrm{~min}$.

In the tests with the amine salts derived from the weak acids, the detected compounds were only the amines. Figure 1c shows the mean concentration value of ChAm detected in the tests with the salts of crotonic acid (ChAm-CroAc) and caprylic acid (ChAm-CapAc).
It is noted that the ChAm from the salts is detected much longer than the pure ChAm assay. Among ChAm-CapAc and ChAm-CroAc salts, ChAm is more easily volatilized from the ChAm-CapAc salt than from the ChAm-CroAc salt. That is, the volatility of ChAm is affected by the type of acid used to form the salt. The concentrations of DchAm detected in the tests with the salts of crotonic acid (DchAc-CroAc) and caprylic acid (DchAm-CapAc) varies with time. It is noted that the detected concentrations of DchAm from the salts are close to the amines in the pure DchAm assay. However, at long times, the concentration of DchAm-CroAc is slightly higher than that of the DchAmCapAc salt.

Figure $1 \mathrm{~d}$ shows the compounds detected in the assays with two $6 \mathrm{~mm}$ aperture vials containing an amine and an acid. In the assay with one vial containing ChAm and another with CroAc, it is observed that only ChAm is detected. In the assay with a flask containing DchAm and another CroAc it is noted that only the CroAc is detected. In these two experiments the compounds detected are those that present higher vapor pressure in relation to the compound that was not detected. This is because compounds with a higher vapor pressure, upon reaching the vial of the compound with lower pressure, neutralize forming a salt of the amine with the acid, hindering the diffusion of these compounds.

In the two types of studied devices, one with a $23 \mathrm{~mm}$ opening and the other with $6 \mathrm{~mm}$, it is noted that the difference between them is the vapor saturation time that changes according to the opening of the device, that is, the greater the exposed area of VCI the more rapidly the vapor pressure will be reached. Furthermore, in another studied system with two separate $6 \mathrm{~mm}$ devices placed in the same environment to mix the components of an acid and an amine in the vapor phase failed, because only the most volatile compound predominates in the vapor phase.

Characterization by surface-enhanced Raman spectroscopy (SERS)

The normal Raman dispersion depends on many factors of sample volume such as the cross-sectional

Table 1. Analytical parameters of the HPLC-UV calibration curves

\begin{tabular}{lccc}
\hline Compound & $y=\mathrm{m} x+\mathrm{b}$ & $\mathrm{r}^{2}$ & Retention time / min \\
\hline ChAm & $y=(34.1 \pm 0.2) x+(0.04 \pm 0.01)$ & 0.999 & 14.2 \\
DchAm & $y=(1.3 \pm 0.1) x+(0.042 \pm 0.007)$ & 0.965 & 27.1 \\
CroAc & $y=(1.02 \pm 0.03) x+(0.014 \pm 0.001)$ & 0.999 & 4.7 \\
CapAc & $y=(0.124 \pm 0.001) x+(0.002 \pm 0.001)$ & 0.999 & 11.3 \\
\hline
\end{tabular}

$\mathrm{r}^{2}$ : coefficient of determination; ChAm: cyclohexylamine; DchAm: dicyclohexylamine; CroAc: crotonic acid; CapAc: caprylic acid. 

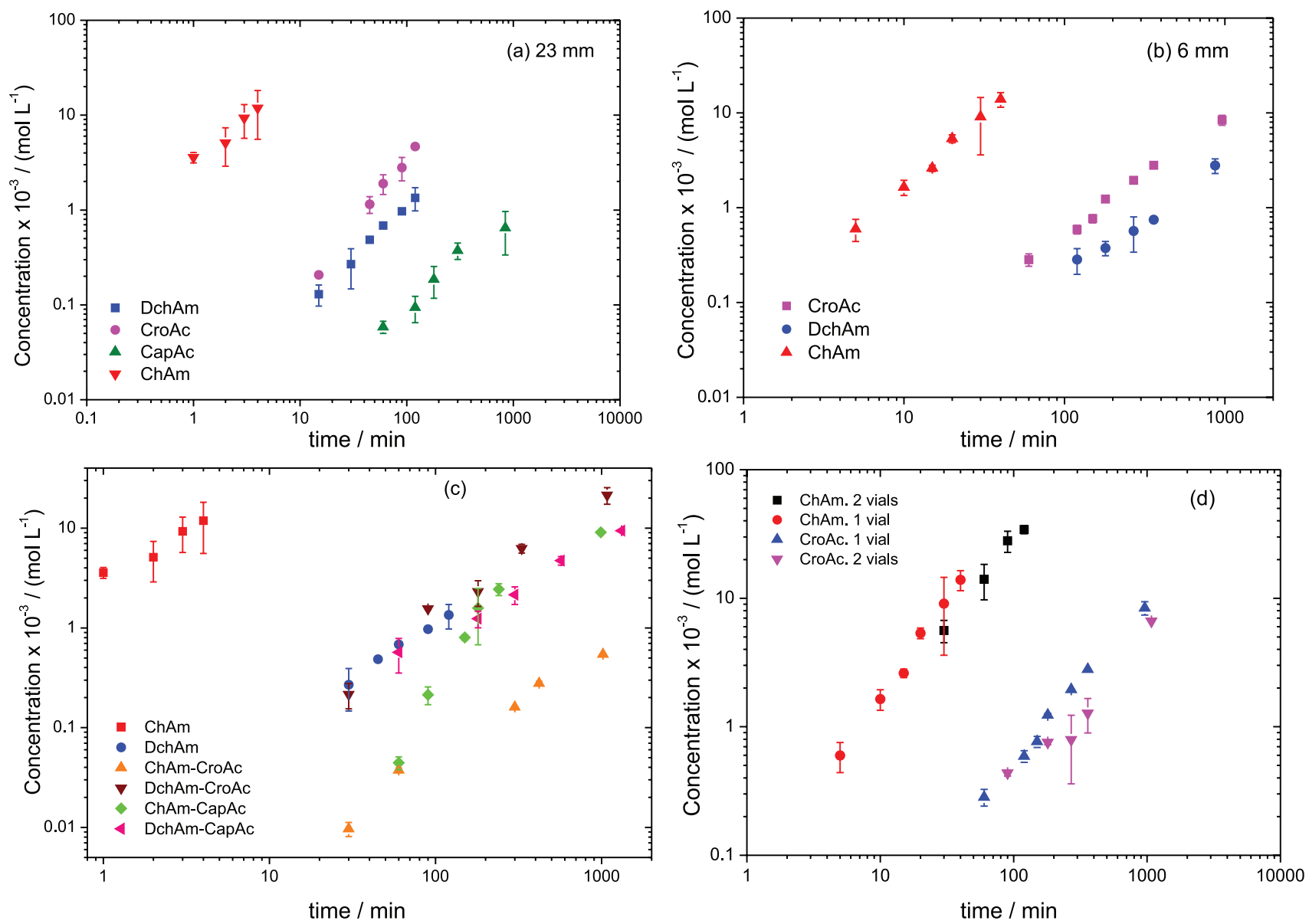

Figure 1. The mean concentration values of the compounds in phosphate buffer solution $\mathrm{pH} 7.2$ (acceptor) stored in vials with apertures of (a) $23 \mathrm{~mm}$; (b) $6 \mathrm{~mm}$; (c) VCI salts and (d) 2 or 1 vial of $6 \mathrm{~mm}$.

dispersion of molecules, optical focal length, and surface transparency. Thus, normal Raman spectroscopy is not suitable for studying surface films and adsorption of molecules. ${ }^{33}$ For this reason, the SERS effect is generally used to isolate surface phenomena, such as adsorption and passive film formation ${ }^{36}$ since it exploits the increase of the Raman scatter signal in the cross section in millions of times by the local field effects of metal nanoparticles such as $\mathrm{Ag}$ or Au. However, the presence of these nanoparticles can influence the electrochemistry and adsorption of molecules on the surface of interest, such as iron. In this study, for detecting VCI on the steel surface, it was necessary to deposit Ag nanoparticles on the surface, which induces an increase in the spreading signal on the surface (SERS effect) and, thus, the presence of the inhibitors on the surface can be easily detected. ${ }^{33}$ For obvious reasons SERS was not used for samples submitted to corrosion and EIS measurements.

Figure 2 shows the spectra obtained by SERS of the steel plates with silver nanoparticles, before any treatment and after a 24-h exposition to ChAm and CroAc. Initially, one can find peaks attributed to several polymorphs iron(III) oxide, namely $\alpha-\mathrm{Fe}_{2} \mathrm{O}_{3}\left(220 \mathrm{~cm}^{-1}\right)$ and $\gamma-\mathrm{Fe}_{2} \mathrm{O}_{3}(1200,1410$ and $2908 \mathrm{~cm}^{-1}$ ); peaks attributed to several polymorphs iron(III) oxide-hydroxide, namely $\alpha-\mathrm{FeOOH}$ (goethite, $1301 \mathrm{~cm}^{-1}$ ) and $\beta$-FeOOH (akaganeite, $1410 \mathrm{~cm}^{-1}$ ); peak attributed to iron(II) hydroxide $\left(\mathrm{Fe}(\mathrm{OH})_{2}: 550 \mathrm{~cm}^{-1}\right)$; and peaks attributed to iron(II,III) oxide $\left(\mathrm{Fe}_{3} \mathrm{O}_{4}: 680\right.$ and $\left.1600 \mathrm{~cm}^{-1}\right) \cdot 37,38$ In the spectrum of the plates exposed to ChAm, one can find the peaks that can be attributed to ChAm, namely the 779 and $843 \mathrm{~cm}^{-1}$ due to ring stretching, $779 \mathrm{~cm}^{-1}$ due to $\mathrm{CH}_{2}$ wagging, $2853 \mathrm{~cm}^{-1}$ due to $\mathrm{CH}_{2}$ symmetric stretching, and $2934 \mathrm{~cm}^{-1}$ due to $\mathrm{CH}_{2}$ asymmetric stretching. ${ }^{39}$ Moreover, there is a decrease in the $\mathrm{Fe}(\mathrm{OH})_{2}$ peak $\left(550 \mathrm{~cm}^{-1}\right)$, indicating that some hydroxides might have been dissolved and replaced by amines. In the spectrum of the plates exposed to CroAc, there is a small increase around $1650 \mathrm{~cm}^{-1}$, explained by the vibration from the Cro's $\mathrm{C}=\mathrm{C} .{ }^{40}$ Furthermore, there is a peak increase around 1410 and $1461 \mathrm{~cm}^{-1}$, which means a probable increase in $\gamma-\mathrm{Fe}_{2} \mathrm{O}_{3}$, a product of corrosion.

Figures 3a-3d show ex situ scanning electron microscopy (SEM) images comparing corrosion results with $\mathrm{NaCl}$ in atmospheres containing ChAm and CroAc after $24 \mathrm{~h}$. In 


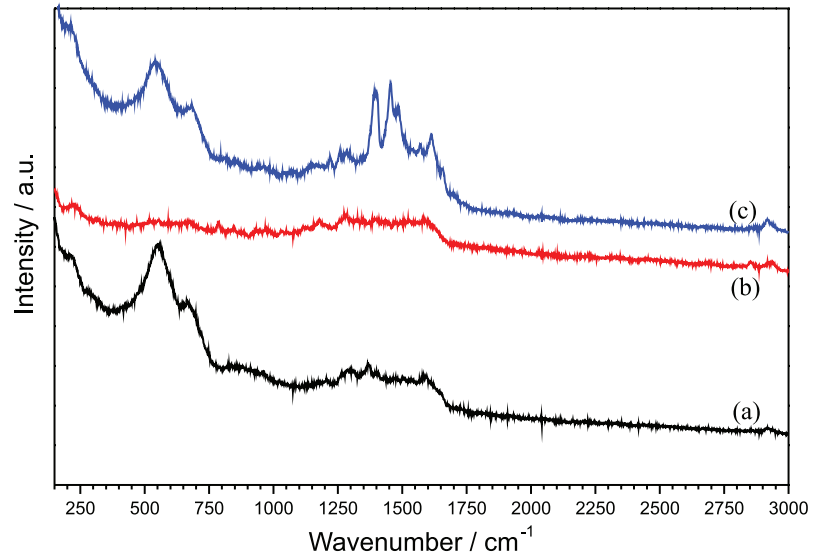

Figure 2. Raman spectra of (a) steel plates with Ag nanoparticles deposited; (b) steel plates with Ag nanoparticles deposited exposed to an atmosphere of ChAm during a period of $24 \mathrm{~h}$; (c) steel plates with $\mathrm{Ag}$ nanoparticles deposited exposed to an atmosphere of CroAc during a period of $24 \mathrm{~h}$.

the atmosphere containing CroAc, the corroded surface is like that observed in the absence of inhibitor. However, with $\mathrm{ChAm}$ the surface remains mostly unaltered, though some regions appear as fine plates (flowery structures) typical of lepidocrocite $(\gamma-\mathrm{FeOOH}){ }^{41}$

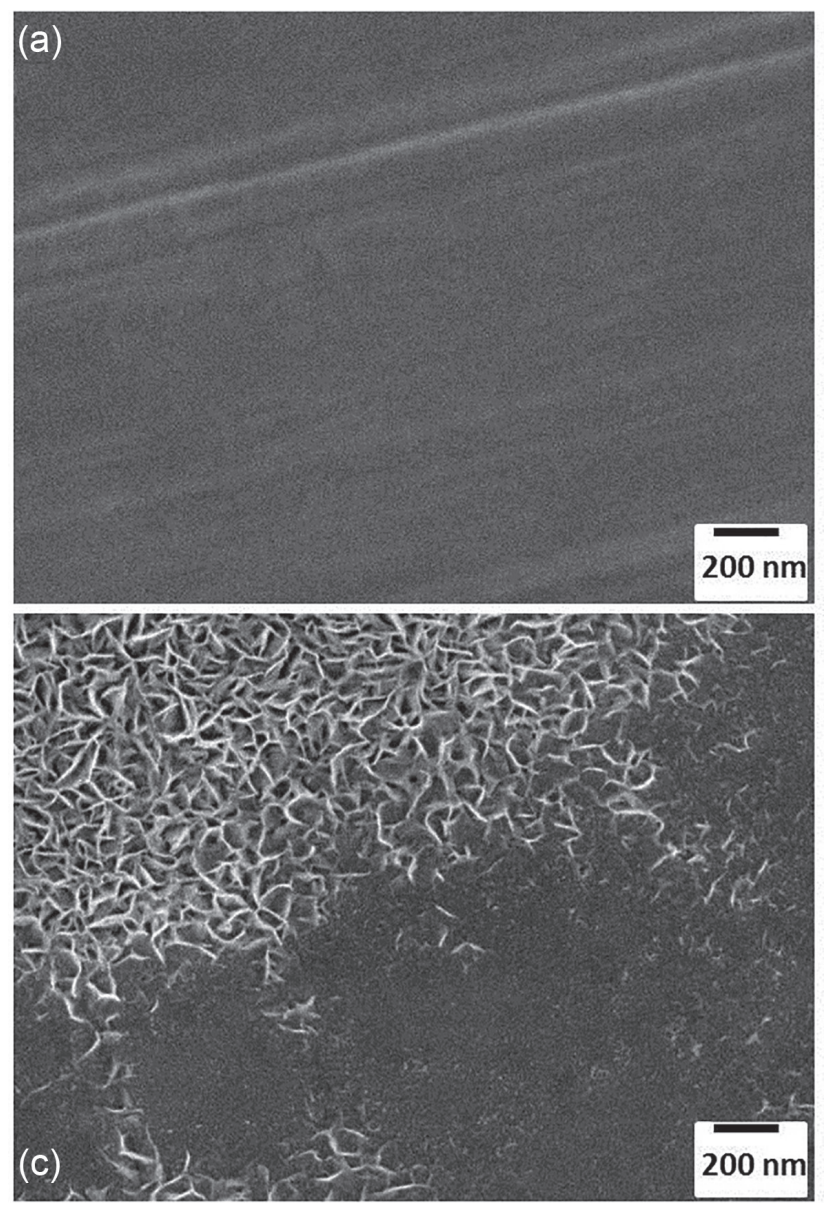

\section{Measurements of mass loss and EIS}

The most traditional methodology to evaluate the corrosion of materials is the mass loss. The mass loss $(\Delta \mathrm{m}$, in $\mu \mathrm{g})$ was determined by quantifying the $\mathrm{Fe}^{3+}$ ions by UV-Vis spectrophotometry after removing the corrosion products from the plates surface. The rate of corrosion $(v)$, in $\mu \mathrm{g} \mathrm{cm}^{-2} \mathrm{~h}^{-1}$, was calculated using the following equation: ${ }^{6}$

$v=\frac{\Delta \mathrm{m}}{\mathrm{At}}$

where $\mathrm{A}$ is the exposed area in $\mathrm{cm}^{2}$ and $\mathrm{t}$ is the time in $\mathrm{h}$. Then, the efficiencies of the deliquescence inhibition $\left(\eta_{v}\right.$, in $\%$ ) were calculated using the following equation:

$\eta_{v}(\%)=\left(1-\frac{v_{\mathrm{VCI}}}{v_{0}}\right) \times 100$

where $v_{\mathrm{VCI}}$ and $v_{0}$ are the corrosion rates in the presence and absence of the VCI, respectively. The degree of coverage $\theta$ of each inhibitor can be found by dividing $\eta_{v}$ by 100 .
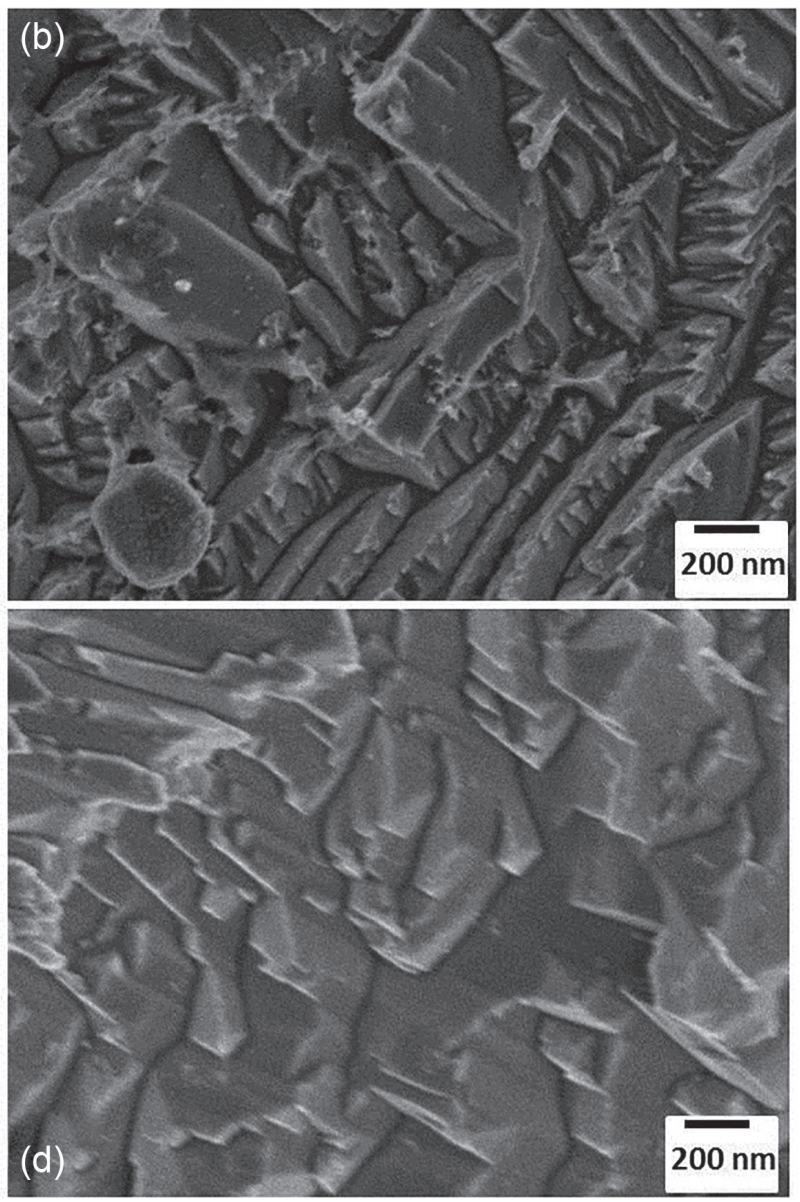

Figure 3. SEM images of the steel plates: (a) before any exposition; (b) $24 \mathrm{~h}$ exposition to an atmosphere without any inhibitor; (c) $24 \mathrm{~h}$ exposition to an atmosphere with ChAm; (d) $24 \mathrm{~h}$ exposition to an atmosphere with CroAc. 
Another way to determine the inhibition efficiency is to use the polarization resistance $\left(\mathrm{R}_{\mathrm{p}}\right)$ obtained from the EIS technique: ${ }^{42}$

$\eta_{\mathrm{R}_{\mathrm{p}}}(\%)=\left(1-\frac{\mathrm{R}_{\mathrm{p}}}{\mathrm{R}_{\mathrm{pVCI}}}\right) \times 100$

where $\mathrm{R}_{\mathrm{pVCl}}$ and $\mathrm{R}_{\mathrm{p}}$ are the polarization resistance in the presence and absence of the VCI, respectively.

Figure 4 shows the corrosion rate after $24 \mathrm{~h}$ of VCI saturation followed by $24 \mathrm{~h}$ of deliquescence test. ChAm had the minor corrosion rate (ca. $6.7 \mu \mathrm{g} \mathrm{cm}^{-2} \mathrm{~h}^{-1}$ ) followed by DchAm and then the derived salts. The compounds CroAc and CapAc did not have any protective effect; in fact, they seem to even increase the corrosion rate by comparison to the experiment without inhibitor.

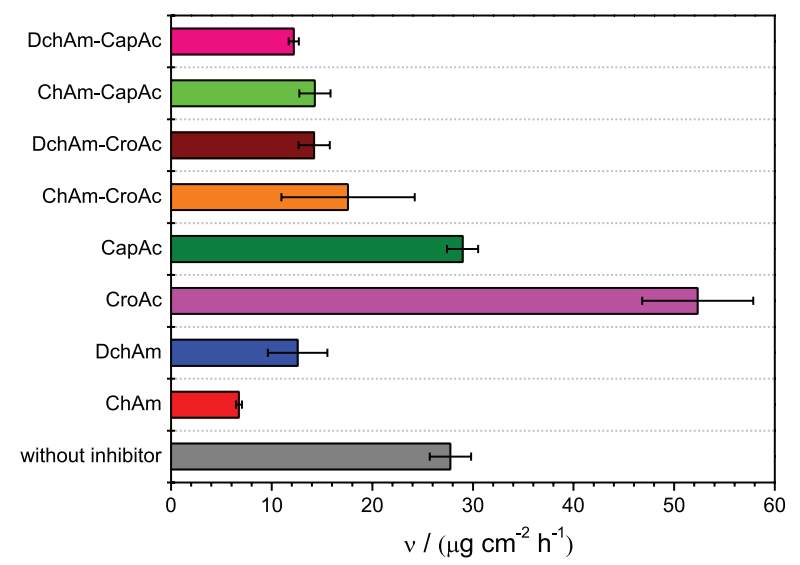

Figure 4. Corrosion rates assays: $24 \mathrm{~h}$ of VCI saturation followed by $24 \mathrm{~h}$ of deliquescence $\mathrm{NaCl}$ in the presence of several inhibitors.

Figure 5 shows the impedance modulus (|Z|) Bode diagrams to steel discs in $\mathrm{NaCl}$ in the presence of several inhibitors. Figure S6 (SI section) shows the corresponding Nyquist and Bode phase angle plots obtained after $6 \mathrm{~h}$ of VCI saturation and $4 \mathrm{~h}$ of deliquescence $\mathrm{NaCl}$ test $(10 \mathrm{~h}$ after $\mathrm{NaCl}$ deposition on the sample). The Nyquist diagrams of steel in the absence and in the presence of inhibitors showed two capacitive semicircles which are better observed in the phase angle Bode plots. The capacitive incomplete semicircle at high frequency values may be related to the formation of an inhibitor film and/or corrosion products, while the capacitive semicircle at low frequencies represents the charge transfer resistance in parallel to electrical double layer capacitance. ${ }^{6}$ However, data at low frequency show a continuous increasing of impedance which could be an indication of a new semicircle or a diffusion-controlled process, but it cannot be distinguished due to the small number of measured frequencies in that region.

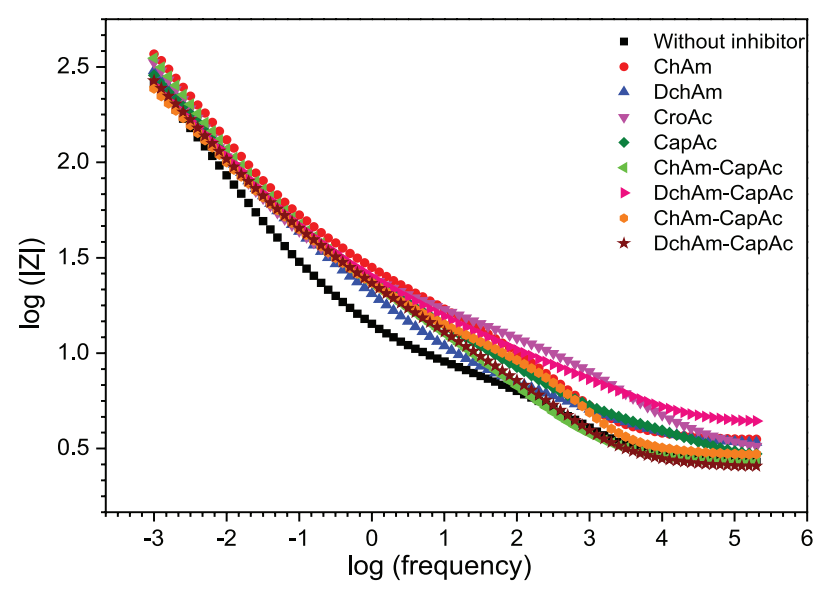

Figure 5. Experimental impedance modulus (|Z|) diagrams performed in deliquescence $\mathrm{NaCl}$ (after $6 \mathrm{~h}$ of $\mathrm{VCI}$ saturation and $4 \mathrm{~h}$ of deliquescence) in the presence of several inhibitors.

From the EIS measurements it was possible to estimate the polarization resistance $\left(R_{\mathrm{p}}\right)$, as the $\log (|\mathrm{Z}|)$ value at the frequency of $1 \mathrm{mHz}$. Although the electrochemical techniques help to elucidate the mechanisms of VCI action, the literature does not show a correlation curve between the efficiency obtained by the electrochemical method in solution and the corrosion rate obtained by mass loss in the vapor phase for several inhibitors. In the present work we tried to do this using EIS measurements in a thin electrolyte layer. Only the conventional electrochemical techniques have been largely used to estimate the efficiency of the VCI, $8,10,13,16,19,20,43$ however, they may fail to determine the VCIs efficiency because they do not take into account that the composition of the VCI in the vapor phase is different from the VCI dissolved in solution. To try a solution of this issue, in this work, electrochemical tests and mass loss measurements were performed using the salt deliquescence phenomenon to simulate the atmospheric condition. ${ }^{6,26}$

The obtained values of corrosion rate $(v)$, polarization resistance $\left(\mathrm{R}_{\mathrm{p}}\right)$ and $\mathrm{pH}_{\mathrm{GDME}}\left(\mathrm{pH}_{\mathrm{ATEL}}\right.$ estimate $)$ are shown in Table 2. It is noted that the high $\mathrm{R}_{\mathrm{p}}$ values of ChAm and ChAm-CapAc agree with the lower values of $v$, indicating that the presence of inhibitor made the corrosion process more difficult. However, this relationship is not true for the CroAc (it is volatile and has high electronic density, but could not be considered a VCI), where the corrosion rate value was higher than in the absence of inhibitor. It means that it facilitates the corrosion of steel, even considering that the $\mathrm{R}_{\mathrm{p}}$ was high, probably due to the deposition/accumulation of corrosion products on the electrode surface, suggesting that EIS testing may not be directly compared to mass loss measurements. This problem arises from the interpretation of $R_{p}$, in which an increase in the impedance at low frequency indicates a decrease in corrosion rate. Therefore, the combination 
of VCI adsorption and corrosion products accumulation on the metallic surfaces could explain, in part, the near $\mathrm{R}_{\mathrm{p}}$ values measured at $1 \mathrm{mHz}$. However, the increase in the resistance in this case may be a consequence of three factors: (i) the first is caused by a decrease in the active area of the electrode after adsorption of the inhibitor; ${ }^{44}$ (ii) the second is caused by the corrosion products that make the corrosion reaction difficult and may even change their mechanism. The corrosion products are generated due to the interaction of alkaline vapor of inhibitor with the steel, resulting in increase of $\mathrm{pH}$ on the surface and (iii) the increase of the area due to the active dissolution of the metal and change in the surface roughness leading to an increase of resistance. Thus, the increase in the $R_{p}$ value of ChAm may be due to the adsorption of the inhibitor and the formation of a layer of oxides and hydroxides (Figure 3c) caused by the high $\mathrm{pH}_{\text {ATEL }}$ values, because when removing the corrosion products in the mass loss cleaning procedure, the surface remains almost unchanged. In the case of CroAc, the increase in $\mathrm{R}_{\mathrm{p}}$ can be attributed to a large accumulation of soluble corrosion products that remain on the surface as a concentrated solution (deliquescence) but are easily removed when the surface is rinsed before measuring the mass loss. This fact is corroborated with SEM images (Figure 3d) that show a corroded surface and without corrosion products deposited. The Raman spectrum data (before electrochemical and corrosion tests) indicates that CroAc is present on the metal surface and, therefore, changes $\mathrm{pH}_{\text {АтеL }}$ to more acidic values, providing the solubilization of corrosion products.

The inhibition efficiency obtained from EIS data is much different than that obtained from mass loss measurements due to the complexity of the corrosion process occurring on the electrode surface: adsorption/desorption of VCI, dissolution of steel and precipitation/accumulation of corrosion products on the electrode with possible variation of the active surface area. These processes are strongly dependent on the $\mathrm{p} K_{\mathrm{a}}$, vapor pressure and solubility of the inhibitor in the thin electrolyte condensed layer. All these factors influence the impedance of the system, making difficult to obtain any correlation between $|Z|$ values and any properties of the inhibitor.

Figure 6 shows a relationship between $v$ and $\mathrm{pH}_{\mathrm{GDME}}$, which results from the inhibitor atmosphere and can be used as an estimation of the $\mathrm{pH}$ of the thin layer of adsorbed electrolyte $\left(\mathrm{pH}_{\text {АтEL }}\right)$ on the metal surface. The higher the $\mathrm{pH}_{\mathrm{GDME}}$ value the lower the corrosion rate $v$ of the steel. The existence of this correlation allows the prediction of possible compounds presenting ability of corrosion inhibition of steel, such as amines ChAm and DchAm with high $\mathrm{p} K_{\mathrm{a}}$ that when dissolved in water maintain high $\mathrm{pH}$ of the solution.

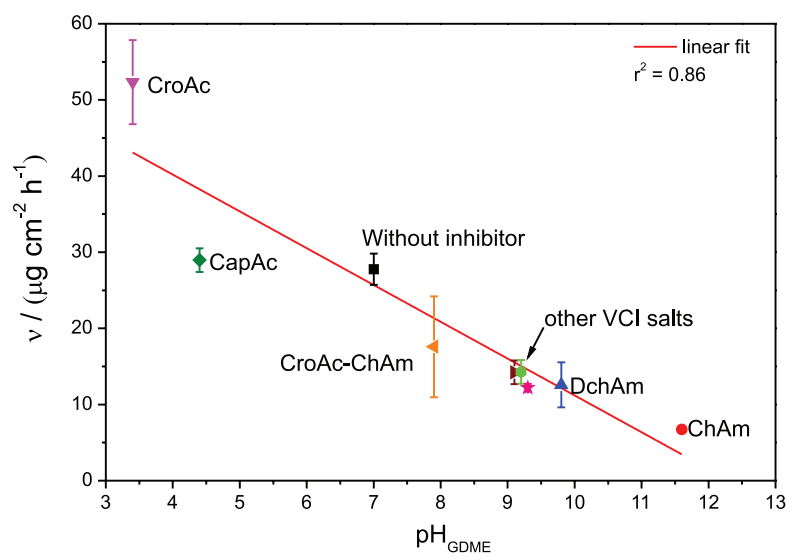

Figure 6. Correlation between $\mathrm{pH}_{\mathrm{GDME}}$ and $v$.

The mechanism of protection of the steel by amino compounds is associated with the high alkalinity of the passive medium of the metal ${ }^{45}$ and the interaction of the

Table 2. Parameters obtained from the mass loss tests, the EIS tests and $\mathrm{pH}$ measurements by the GDME method

\begin{tabular}{|c|c|c|c|c|c|}
\hline Compound & $\mathrm{pH}_{\mathrm{GDME}}$ & $v /\left(\mu \mathrm{g} \mathrm{cm}^{-2} \mathrm{~h}^{-1}\right)$ & $\eta_{v} / \%$ & $\mathrm{R}_{\mathrm{p}} /\left(\Omega \mathrm{cm}^{2}\right)$ & $\eta_{\mathrm{Rp}} / \%$ \\
\hline Without inhibitor & 7.0 & $28 \pm 2$ & - & 258 & - \\
\hline ChAm & 11.6 & $6.7 \pm 0.3$ & 75.7 & 369 & 30.1 \\
\hline DchAm & 9.8 & $13 \pm 3$ & 54.7 & 302 & 14.5 \\
\hline CroAc & 3.4 & $52 \pm 6$ & -88.5 & 333 & 22.5 \\
\hline CapAc & 4.4 & $29 \pm 2$ & -4.5 & 286 & 9.7 \\
\hline ChAm-CroAc & 7.9 & $18 \pm 7$ & 36.7 & 243 & -6.1 \\
\hline DchAm-CroAc & 9.1 & $14 \pm 2$ & 48.8 & 267 & 35.3 \\
\hline ChAm-CapAc & 9.2 & $14 \pm 2$ & 48.5 & 351 & 26.5 \\
\hline DchAm-CapAc & 9.3 & $12.2 \pm 0.5$ & 56.1 & 253 & -1.7 \\
\hline
\end{tabular}

GDME: gas-diffusion microextraction; $v$ : corrosion rate; $\eta_{v}$ : deliquescence inhibition; $R_{\mathrm{p}}$ : polarization resistance; $\eta_{\mathrm{Rp}}$ : inhibition efficiency; ChAm: cyclohexylamine; DchAm: dicyclohexylamine; CroAc: crotonic acid; CapAc: caprylic acid. 
nitrogen atom with the surface. ${ }^{6}$ It is well known that VCI performance is directly related to the stability of the primary oxide layers present on the metals surface, depending on the VCI mixture used, the $\mathrm{pH}_{\mathrm{ATEL}}$ can be altered and destabilize the oxides and can induce corrosion. ${ }^{46}$ The high value of $\mathrm{p} K_{\mathrm{a}}$ of the VCI can indicate a passivation effect on the steel by increasing the $\mathrm{pH}_{\mathrm{ATEL}}$, since the steel can be passivated at $\mathrm{pH}>11 .{ }^{47}$ However, there is a difference between ChAm and DchAm, this may be due to the solubility and vapor pressure of such compounds. When there is high relative humidity in the container where the steel is stored, a thin layer of electrolyte is formed on the surface $^{15}$ and, therefore, an inhibitor with high solubility and vapor pressure is present in high concentration in this thin layer of electrolyte, contributing to a better inhibition efficiency. The high vapor pressure always allows the action of the inhibitor, justifying the lowest $v$ obtained with ChAm, since this compound presents high values of $\mathrm{p} K_{\mathrm{a}}$, solubility and vapor pressure. While DchAm, although having a high $\mathrm{p} K_{\mathrm{a}}$, does not exhibit the same efficiency due to its low solubility and vapor pressure. In a similar manner, acid compounds accelerate corrosion, because in acidic medium the steel is corroded by the dissolution or solubilization of the primary oxide layer.

In the case of VCI salts, as discussed and observed, the compounds detected in the vapor phase are the amines, however, to a lesser extent than the pure amines. For this reason, the VCI salts reduce $v$ of the steel, however, it does not reduce as efficiently as the pure amines DchAm and ChAm. On the other hand, the inhibitory capacity of carboxylic acids is a consequence of a synergistic action between dissolved oxygen and carboxylate anions. ${ }^{48}$ In addition, salts of weak acids passivate iron in oxygenated solutions only when the $\mathrm{pH}$ and concentration of the solution exceeds a critical value. ${ }^{49}$ In the case of caprylates, the critical concentration is $\geq 0.010 \mathrm{~mol} \mathrm{~L}^{-1}$ and the critical $\mathrm{pH} \geq 5$.9. The passivation of the steel by the caprylic ions is due to the blocking by insoluble complexes of iron(III) carboxylates that are formed in the defects of the primary oxide layer. ${ }^{30}$

\section{Conclusions}

The steel protection by amines, carboxylic acids and the respective salts was investigated in the presence of vapor of those compounds and in $\mathrm{NaCl}$ thin layer deposited on the steel. The inhibition efficiency evaluated by loss mass, the VCI vapor composition measured in real time by GDME followed by HPLC-UV analysis and the modifications on the steel surface analyzed by SERS in situ and SEM were discussed and the following conclusions can be drawn: (i) VCI vapor pressure is a determinant parameter for the atmosphere saturation and in a VCI mixture, the one with higher vapor pressure dominates the corrosion process; (ii) the resulting $\mathrm{pH}$ from the VCI atmosphere $\left(\mathrm{pH}_{\mathrm{GDME}}\right)$ strongly contributes to steel protection, even modifying the mechanism. The base protection mechanism is the molecule adsorption from the saturated atmosphere and the modification of the primary oxide layer composition due to the $\mathrm{pH}$ variations at the metal surface; (iii) our results indicated cyclohexylamine and dicyclohexylamine and their caprylates salts are the more efficient inhibitors and then, potential candidates to be used in field tests; (iv) the use of crotonic acid and caprylic acid are not recommended as they increase the corrosion rate of steel; (v) the methodology developed can be used to classify the inhibitors for field testing, since the operational conditions in laboratory and field are similar.

\section{Supplementary Information}

Supplementary information is available free of charge at http://jbcs.sbq.org.br as PDF file.

\section{Acknowledgments}

Authors would like to thank FAPESP (2018/14425-7), CAPES (001) and CAPES-FCT (project: 99999.008406/2014-06, Brazil-Portugal) for the scholarships (M. A. G. V. J.) and SERS analysis facilities from the Materiais Fotônicos (IQ-UNESP, Araraquara, Brazil). The authors thank Prof Carlos Manuel de Melo Pereira for the facilities.

\section{Author Contributions}

Marco A. G. Valente Jr. was responsible for the conceptualization, data curation, formal analysis, investigation, methodology, validation, visualization and writing original draft; Luís M. Gonçalves for the methodology, visualization and writing original draft; Juliano Passaretti Filho for the formal analysis; Arnaldo A. Cardoso for the conceptualization, funding acquisition, methodology and resources; José A. Rodrigues for the resources; Cecilio S. Fugivara for the conceptualization, methodology, resources, visualization and writing original draft; Assis V. Benedetti for the funding acquisition, resources, visualization, writing original draft and corrections.

\section{References}

1. Vuorinen, E.; Kálmán, E.; Focke, W.; Surf. Eng. 2004, 20, 281. 
2. Bastidas, D. M.; Cano, E.; Mora, E. M.; Anti-Corros. Methods Mater. 2005, 52, 71.

3. Ansari, F. A.; Verma, C.; Siddiqui, Y. S.; Ebenso, E. E.; Quraishi, M. A.; Int. J. Corros. Scale Inhib. 2018, 7, 126.

4. Quraishi, M. A.; Bhardwaj, V.; Rawat, J.; J. Am. Oil Chem. Soc. 2002, 79, 603.

5. Vuorinen, E.; Skinner, W.; Br. Corros. J. 2002, 37, 159.

6. Chen, J.; Chen, Z.; Guo, X.; J. Electrochem. Soc. 2014, 161, C151.

7. Estevão, L. R. M.; Nascimento, R. S. V.; Corros. Sci. 2001, 43, 1133.

8. Quraishi, M. A.; Ansari, F. A.; Rawat, J.; Open Electrochem. J. 2009, 1, 32 .

9. Belarbi, Z.; Farelas, F.; Singer, M.; Nešić, S.; Corrosion 2016, 72,1300 .

10. Gao, G.; Liang, C. H.; Corros. Sci. 2007, 49, 3479.

11. Kannan, P.; Lavanya, K.; Natesan, M.; Res. J. Chem. Sci. 2012, 2,50 .

12. Rammelt, U.; Koehler, S.; Reinhard, G.; Corros. Sci. 2009, 51, 921.

13. Rammelt, U.; Koehler, S.; Reinhard, G.; Corrosion 2011, 67, 045001-1.

14. Zhang, D. Q.; Gao, L. X.; Zhou, G. D.; Mater. Corros. 2007, $58,594$.

15. Chen, Z.; Huang, L.; Zhang, G.; Qiu, Y.; Guo, X.; Corros. Sci. 2012, 65, 214.

16. Sieber, M.; Lautner, S.; Faßbender, F.; Int. J. Corros. Scale Inhib. 2019, 8, 908.

17. Premkumar, P.; Kannan, K.; Natesan, M.; Arabian J. Sci. Eng. 2009, 34, 71.

18. Sudheer; Quraishi, M. A.; Ebenso, E. E.; Natesan, M.; Int. J. Electrochem. Sci. 2012, 7, 7463.

19. Teixeira, D. A.; Valente Jr., M. A. G.; Benedetti, A. V.; Feliciano, G. T.; da Silva, S. C.; Fugivara, C. S.; J. Braz. Chem. Soc. 2015, 26, 434.

20. Valente Jr., M. A. G.; Teixeira, D. A.; Azevedo, D. L.; Feliciano, G. T.; Benedetti, A. V.; Fugivara, C. S.; Front. Chem. 2017, 5, 32.

21. Nhlapo, N. S.; Focke, W. W.; Vuorinen, E.; Thermochim. Acta 2012, 546, 113.

22. Focke, W. W.; Nhlapo, N. S.; Vuorinen, E.; Corros. Sci. 2013, 77,88 .

23. da Silva, L. C.; Pereira, E. A.; Cardoso, A. A.; Measurement 2015, 60, 276.

24. Skinner, W.; Corros. Sci. 1993, 35, 1491.

25. Wan, H. J.; Huang, H. J.; Zhang, M.; Li, Z. G.; J. Cent. South Univ. Technol. (Engl. Ed.) 2005, 12, 406.

26. Weissenrieder, J.; Leygraf, C.; J. Electrochem. Soc. 2004, 151, B165.
27. Pitombo, L. R. M.; Cardoso, A. A.; Int. J. Environ. Anal. Chem. 1990, 39, 349.

28. Pacheco, J. G.; Valente, I. M.; Gonçalves, L. M.; Rodrigues, J. A.; Barros, A. A.; J. Sep. Sci. 2010, 33, 3207.

29. Valente, I. M.; Santos, C. M.; Gonçalves, L. M.; Rodrigues, J. A.; Barros, A. A.; Anal. Methods 2012, 4, 2569.

30. Reinhard, G.; Radtke, M.; Rammelt, U.; Corros. Sci. 1992, 33 , 307.

31. Gonçalves, L. M.; Magalhães, P. J.; Valente, I. M.; Pacheco, J. G.; Dostálek, P.; Sýkora, D.; Rodrigues, J. A.; Barros, A. A.; J. Chromatogr. A 2010, 1217, 3717.

32. Martins, A. B.; Lobato, A.; Tasic, N.; Perez-Sanz, F. J.; Vidinha, P.; Paixão, T. R. L. C.; Gonçalves, L. M.; Electrochem. Commun. 2019, 106541.

33. Tormoen, G.; Burket, J.; Dante, J. F.; Sridhar, N.; Corrosion 2006, 62, 1082.

34. Filho, J. P.; Valente Jr., M. A. G.; Gomes, P. C. F. L.; Fugivara, C. S.; Cardoso, A. A.; Anal. Methods 2017, 9, 655.

35. Andreev, N. N.; Ibatullin, K. A.; Prot. Met. 2002, 38, 13.

36. Oblonsky, L. J.; Devine, T. M.; Corros. Sci. 1995, 37, 17.

37. Gui, J.; Devine, T. M.; Corros. Sci. 1991, 32, 1105.

38. Dunn, D. S.; Bogart, M. B.; Brossia, C. S.; Cragnolino, G. A.; Corrosion 2000, 56, 470.

39. Darkhalil, I. D.; Klaassen, J. J.; Deodhar, B. S.; Gounev, T. K.; Durig, J. R.; J. Mol. Struct. 2015, 1088, 169.

40. Fausto, R.; J. Mol. Struct. 1996, 377, 181.

41. De la Fuente, D.; Díaz, I.; Simancas, J.; Chico, B.; Morcillo, M.; Corros. Sci. 2011, 53, 604.

42. Fernandes, C. M.; Fagundes, T. D. S. F.; dos Santos, N. E.; Rocha, T. S. M.; Garrett, R.; Borges, R. M.; Muricy, G.; Valverde, A. L.; Ponzio, E. A.; Electrochim. Acta 2019, 312, 137.

43. Gutiérrez, E.; Rodríguez, J. A.; Cruz-Borbolla, J.; AlvaradoRodríguez, J. G.; Thangarasu, P.; Corros. Sci. 2016, 108, 23.

44. Kuznetsov, Y. I.; Andreev, N. N.; Vesely, S. S.; Int. J. Corros. Scale Inhib. 2015, 4, 108.

45. Andreev, N. N.; Goncharova, O. A.; Prot. Met. 2004, 40, 257.

46. Koehler, S.; Reinhard, G.; Int. J. Corros. Scale Inhib. 2014, 3 , 286.

47. Mrowczynski, G.; Szklarska-Smialowska, Z.; J. Appl. Electrochem. 1979, 9, 201.

48. Goncharova, O. A.; Luchkin, A. Y.; Archipushkin, I. A.; Andreev, N. N.; Kuznetsov, Y. I.; Vesely, S. S.; Int. J. Corros. Scale Inhib. 2019, 8, 586.

49. Forker, W.; Reinhard, G.; Rahner, D.; Corros. Sci. 1979, 19, 745.

Submitted: February 10, 2020

Published online: June 1, 2020 